\title{
Nerve compression injury and increased endoneurial fluid pressure: a "miniature compartment syndrome"
}

\author{
GÖRAN LUNDBORG, ROBERT MYERS, HENRY POWELL \\ From the Division for Hand Surgery, Department of Orthopedics, University of Lund, Departments of \\ Orthopedics and Rehabilitation and of Neurosciences, Anesthesiology and Pathology (Neuropathology), \\ University of California, San Diego, School of Medicine, La Jolla, CA., and the Veterans Administration \\ Medical Center, San Diego, CA, USA
}

SUMMARY An inflatable miniature cuff was used to apply local compression of $80 \mathrm{~mm} \mathrm{Hg}$ or $30 \mathrm{~mm} \mathrm{Hg}$ to a segment of rat sciatic nerve for time periods varying from two to eight hours. The endoneurial fluid pressure was measured by direct micropipette measurement techniques at one or 24 hours after removal of the cuff, and the nerves were subjected to histological analysis. Endoneurial oedema, associated with a four-fold increase in endoneurial fluid pressure, was observed after compression at $80 \mathrm{~mm} \mathrm{Hg}$ for four hours, and a three-fold increase was found after compression at 30 or $80 \mathrm{~mm} \mathrm{Hg}$ for eight hours. Such an increase in endoneurial fluid pressure may interfere with intrafascicular capillary flow, and thereby constitute an important pathophysiological mechanism in nerve compression injuries.

The pathophysiological mechanisms of acute and chronic nerve compression injuries are not completely understood, although considerable knowledge has accumulated during recent years. In acute compression lesions, for example tourniquet palsy and other conditions where pressure of high magnitude has been directly applied to a nerve trunk, the resulting disturbances in nerve function are based mainly upon local myelin changes under the edge of the cuff. The redistribution of tissue from compressed to non-compressed levels of the nerve is associated with invagination of the myelin sheaths at the nodes of Ranvier. ${ }^{12}$ The resulting myelin damage is associated with partial or complete local conduction block, usually reversible within weeks or months. Also a possible microvascular factor has been considered as irrelevant by Williams et al, ${ }^{3}$ and we have demonstrated the occurrence of endoneurial oedema in the transitional zones of a nerve segment, subjected to higher pressure. ${ }^{4}$ During certain circumstances this oedema may be associated with a no-reflow phenomenon in the affected nerve segment. ${ }^{5}$

Address for reprint requests: Göran Lundborg, MD. Div for Hand Surgery, Lunds University Hospital, S-221 85 Lund, Sweden.

Received 1 February 1983 and in revised form 7 May 1983. Accepted 28 June 1983.
Chronic nerve compressions may be more complicated in their general pathophysiology, since the local anatomy at different common entrapment levels of the extremities may vary with respect to size and shape of extraneural tissue compartments, muscles and fascia edges, as well as the force applied to the nerve (stretch-bending-compression). It has also been suggested that in these cases the symptoms presented are based exclusively on local myelin changes in the affected nerve segment. ${ }^{6}$ However, it is a common clinical experience, that even chronic entrapments with longstanding muscle weakness and sensory disturbances sometimes show a very rapid reversibility of some or all of the symptoms after surgical decompression of the nerve. These findings suggest the existence of a local metabolic block in the compressed segment of the nerve. The rapid reversibility indicates that such a disturbance may be based upon temporary microvascular disorder in the compressed part of the nerve in addition to local myelin changes. ${ }^{7-9}$

In recent investigations we have studied the effects of compression on intraneural microvascular flow. ${ }^{5}$ The present study was concerned with the microvascular factors in experimental nerve compression injuries, this time with special reference to the occurrence of an intrafascicular oedema with corresponding increase in endoneurial fluid pressure at the site of injury. The study was made possible by 
the use of micropipette techniques for direct measurements of the endoneurial fluid pressure. ${ }^{10}$

\section{Material and methods}

Adult Sprague-Dawley rats weighing 250-300 grams were anaesthetised by intraperitoneal injection of a solution composed of Nembutal $(50 \mathrm{mg} / \mathrm{ml})$, saline and diazepam $(5 \mathrm{mg} / \mathrm{ml})$ in volume proportions of 1:1:2.

\section{Compression procedure}

The sciatic nerve of the left midthigh was exposed by a lateral incision. The nerve was compressed by a special compression chamber constituting a smaller modification of the chamber described in detail by Rydevik and Lundborg. ${ }^{4}$ This compression device consists of two symmetrical halves of plexi-glass into which thin rubber membranes are glued. The two halves were placed around the nerve trunk and joined by four small screws. The chamber was connected to a servo pressure system (AB Stille-Werner, Stockholm) allowing inflation of the rubber cuffs in the chamber to a desired pressure. The system automatically compensated for any leakage of air, thus maintaining the pressure of the system at a constant level. The length of the compressed nerve segment was approximately $3 \mathrm{~mm}$. After the compression chamber was secure, the skin was sutured, thereby allowing only the connecting tubes to penetrate the skin into the wound.

\section{Animal experiments}

In one series of animals $(n=4)$, a pressure of $30 \mathrm{~mm} \mathrm{Hg}$ was applied to the nerves for $2,4,6$ and 8 hours. In another series $(n=4)$, a pressure of $80 \mathrm{~mm} \mathrm{Hg}$ was applied for the same time periods. In four animals, sham experiments were performed so that only the chamber was applied around the nerve for 2, 4, 6 and 8 hours without being inflated. The pressure levels of 30 and $80 \mathrm{~mm} \mathrm{Hg}$ were chosen because it is known from previous experiments $^{5}$ that these pressures will interfere with intraneural venular flow $(30 \mathrm{~mm} \mathrm{Hg}$ ) or cause a circulatory arrest in the nerve $(80 \mathrm{~mm} \mathrm{Hg})$.

After the compression periods, the skin was opened and the compression device removed. One hour or 24 hours later a direct measurement of the endoneurial fluid pressure was performed as described below. The animal was then killed by an overdose of Nembutal, and the nerve was removed for histological analysis.

\section{Measurement of endoneurial fuid pressure}

Endoneurial fluid pressure was measured directly with a servo-null micropipette system by inserting the tip of a glass micropipette (4 microns diameter) through the perineurial membrane into the endoneurium, a method which has been described in detail elsewhere by Myers $e t$ al. ${ }^{10}$ The measurements were made in the transitional zone between compressed and non-compressed parts of the nerve, under the edge of the cuff, since we know from previous experiments ${ }^{4}{ }^{10}$ that the maximal structural and functional injury is induced in the nerve at this level. For each animal, three or more recordings were taken and averaged together. The nerve was surrounded and irrigated with a physiological salt solution which was bicarbonate-buffered and temperature controlled. All endoneurial fluid pressure measurements were referenced to atmospheric pressure by establishing a baseline pressure from the fluid bath surrounding the nerve.

\section{Histological analysis}

After measurement of endoneurial fluid pressure, the sciatic nerve was removed and processed for light microscopy by fixation in $2.5 \%$ phosphate-buffered glutaraldehyde, post-fixation in osmium tetroxide, dehydration in serial alcohols and embedded in araldite. One-micron-thick sections were stained with paraphenylenediamine for light microscopic analysis.

\section{Results}

\section{Endoneurial fluid pressure}

The results from the pressure measurements are presented in fig 1 .

\section{$80 \mathrm{~mm} \mathrm{Hg}$}

After compression periods up to 4 hours there was a continuous increase in endoneurial fluid pressure as revealed by measurements one hour as well as 24 hours after release of the compression. The maximal endoneurial fluid pressure was recorded 24 hours after compression for 4 hours when the endoneurial fluid pressure was $8.5 \mathrm{~cm} \mathrm{H}_{2} \mathrm{O}$, that is more than four times the normal pressure. Extending the period of compression more than 4 hours did not increase the endoneurial fluid pressure; on the contrary, there was a tendency to decrease endoneurial fluid pressure with longer periods of compression. Following 8 hours compression, endoneurial fluid pressure was $5.8 \mathrm{~cm} \mathrm{H}_{2} \mathrm{O}$, at one-hour as well as 24 hours after release of the compression cuff.

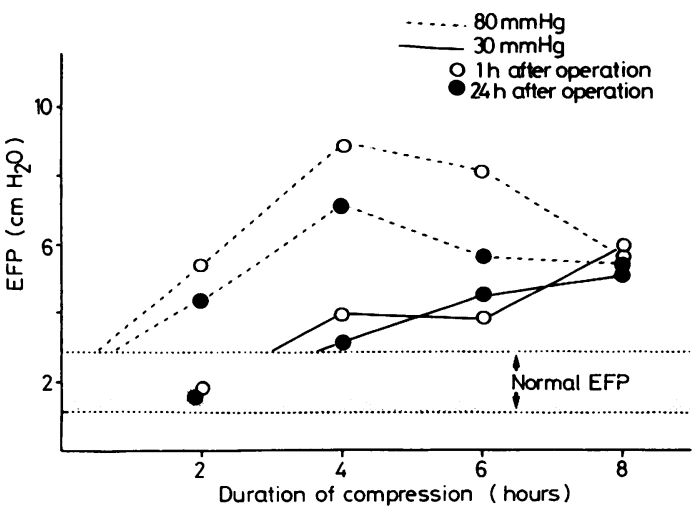

Fig 1 Graphical results of changes in endoneurial fuid pressure associated with nerve compression at different pressure levels for various periods of time. Normal endoneurial fluid pressure is $2.0 \pm 1.0 \mathrm{~cm} \mathrm{H}_{2} \mathrm{O}$; elevation of endoneurial fluid pressure beyond normal levels is plotted. 


\section{$30 \mathrm{~mm} \mathrm{Hg}$}

Two hours of compression was not followed by a detectable increase in endoneurial fluid pressure, while longer periods of compression induced a continuous increase in endoneurial fluid pressure lasting at least 24 hours. The maximal increase of endoneurial fluid pressure was observed following 8 hours compression. Endoneurial fluid pressure was found to be approximately $6.0 \mathrm{~cm} \mathrm{H}_{2} \mathrm{O}$, that is nearly the same as after compression at $80 \mathrm{~mm} \mathrm{Hg}$ for 8 hours.

\section{Sham experiments}

Application of the chamber around the nerve for 2-8 hours without inflating it did not result in any increase of endoneurial fluid pressure above normal values $\left(2.0 \pm 1.0 \mathrm{~cm} \mathrm{H}_{2} \mathrm{O}\right)$.

\section{Histology}

No histologic changes were observed in shamoperated rat nerves (fig 2). There was a strong correlation between the recorded endoneurial fluid pressure and the histological appearance of the corresponding nerve segment. Endoneurial oedema was most prominent in nerves compressed for 4 hours at a pressure of $80 \mathrm{~mm} \mathrm{Hg}$. The sections showed widely separated nerve fibres with extensive oedema most prominent in the subperineurial space (fig 3 ). This was observed in nerves subjected to a pressure

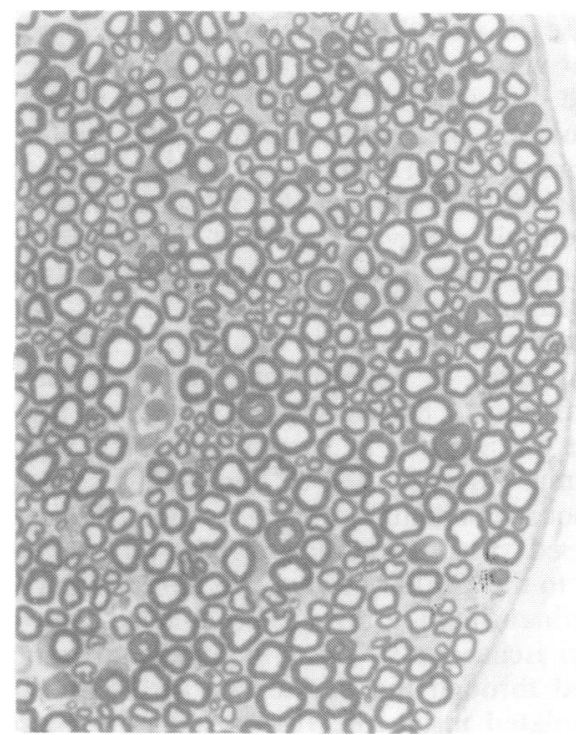

Fig 2 Light micrograph of major fascicle from sciatic nerve of Sprague-Dawley rat after sham experiment in which the pressure cuff was placed around the nerve but not inflated. Fascicle appears normal with tightly packed axons in close association with perineurium. $(\times 500)$

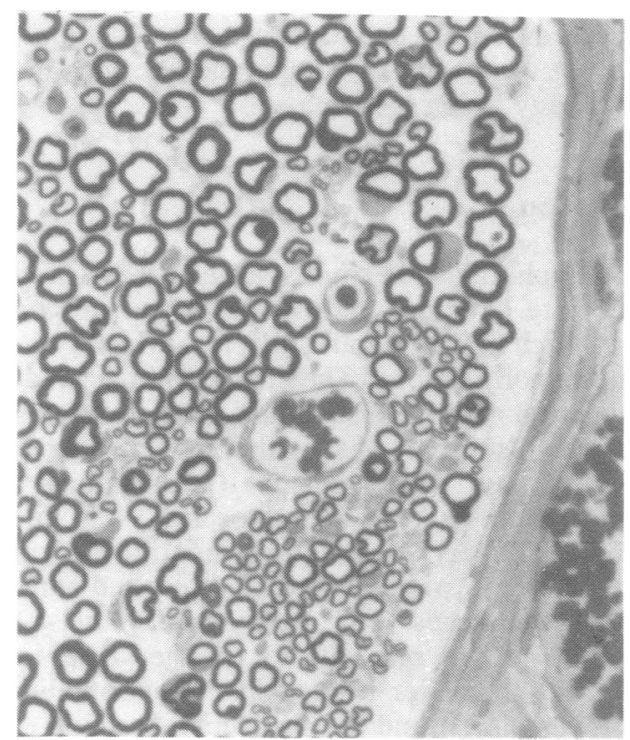

Fig 3 Light micrograph of major fascicle from sciatic nerve of rat which was compressed at a pressure of $80 \mathrm{~mm}$ $\mathrm{Hg}$ for 4 hours. Note extensive oedema in sub-perineurial and perivascular spaces. Oedema also separates nerve fibres. $(\times 500)$

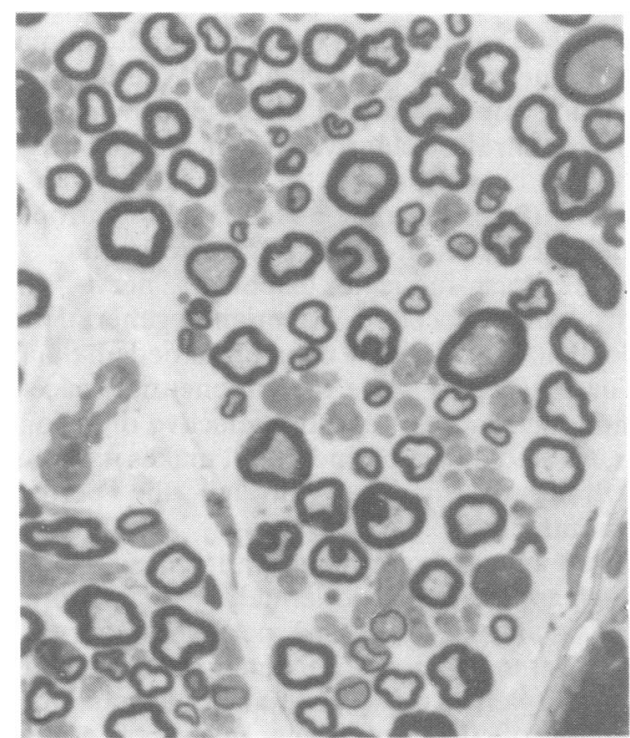

Fig 4 Higher power light micrograph of degenerating nerve fibres 24 hours after compression at $80 \mathrm{~mm} \mathrm{Hg}$ for 4 hours. Note extensive endoneurial oedema. $(\times 1000)$

of $80 \mathrm{~mm} \mathrm{Hg}$ for 2 and 6 hours, while the oedema was less advanced following 8 hours compression. Severe nerve damage was observed in some nerves (fig 4). The nerves compressed at $30 \mathrm{~mm} \mathrm{Hg}$ 
showed moderate oedema only after 8 hours compression while shorter compression periods did not induce any visible oedema.

\section{Discussion}

The peripheral nerve trunk is a well vascularised and composite structure with numerous tissue components, each of which could suffer individually from a compression lesion. The nerve fibres and the intraneural microvessels should be considered separately in this respect. As in other tissues of the body, trauma may alter vascular permeability, and endoneurial oedema may occur..$^{41-15}$ In the epineurium, the vessels are comparatively vulnerable to compression trauma, and respond with permeability changes. The endoneurial vessels, however, are more resistant to change. Due to the blood-nerve-barrier located in the endothelium of these vessels ${ }^{1617}$ and the protective function of the perineurium, ${ }^{18} 19$ oedema is not induced as easily intrafascicularly as extrafascicularly.

However, certain neurological disorders are known to be associated with an endoneurial oedema and an increase in the endoneurial fluid pressure. ${ }^{20}$ Normally, the pressure inside fascicles is $2.0 \mathrm{~cm} \mathrm{H}_{2} \mathrm{O}$ as revealed in experimental animals by direct measurement techniques ${ }^{10}$ or techniques involving implantation of small polyethylene matrix capsules intrafascicularly. ${ }^{21}$ An increase in this pressure has been observed in association with toxic injuries (hexachlorophene and lead neuropathy), metabolic disorders (galactosaemia and streptozotocin-induced diabetes), nerve trauma (crush with associated Wallerian degeneration) and cryogenic lesions..$^{15}{ }^{20}$ Endoneurial oedema may not be drained easily since the endoneurial space lacks lymphatic channels, and the selective diffusion barrier, formed by the perineurium, makes it impossible to drain the oedema through the perineurial membrane.

From animal experiments and clinical experience it is clear that even moderately increased pressure may significantly affect a peripheral nerve. The impulse transmission is dependent on a local energy supply as well as preserved functional and structural integrity of the axoplasma membrane. Thus, it would seem that any disturbance of the intraneural microcirculation or the axoplasmic flow would have secondary effects on the impulse transmission. The data available on "critical pressure levels" in this context are important for our understanding of the pathophysiology of compression neuropathies. In animal experiments it has already been demonstrated that a pressure of $30 \mathrm{~mm} \mathrm{Hg}$ will cause impairment of the intraneural venular flow. ${ }^{5}$ The same magnitude of local pressure blocks the fast axoplasmic flow, as observed in the vagus nerve of rabbits. ${ }^{22}$ Clinically, measurements have been performed on the extraneurial tissue pressure in the carpal tunnel in patients with carpal tunnel syndrome. ${ }^{23}$ The mean pressure was found to be $32 \mathrm{~mm} \mathrm{Hg}$. Also, in experiments where external pressure was applied to the carpal tunnel of volunteers, the first neurophysiological and clinical signs of nerve dysfunction, including paraesthesia of the hand, occurred at a tissue pressure of $30 \mathrm{~mm} \mathrm{Hg}$ in the carpal canal. ${ }^{24}$ The same pressure level, experimentally induced to create compartment syndromes in dogs, was found to induce the first signs of nerve dysfunction. ${ }^{25}$

In the present study a pressure of $30 \mathrm{~mm} \mathrm{Hg}$, applied for eight hours, was followed by a three-fold increase in endoneurial fluid pressure. This increase in endoneurial fluid pressure has to be considered when discussing the pathophysiology of nerve entrapment, for example, the carpal tunnel syndrome. The early phase of this condition is characterised by intermittent paraesthesiae of the hand, most prominent during night time and often completely reversible during day time. The horizontal position of the body in combination with muscle inactivity during sleep may normally result in an increase of tissue pressure in the carpal canal. The carpal tunnel patient has a poor tolerance for any increase in carpal tunnel pressure. When such a patient wakes up early in the morning, the paraesthesiae may well be based upon an impaired microcirculation in the median nerve in combination with an increase in endoneurial fluid pressure. Relief of the symptoms may parallel restoration of normal intraneurial microvascular flow, disappearance of the endoneurial oedema and normalisation of endoneurial fluid pressure.

The maximal increase in endoneurial fluid pressure in our series of experiments was seen following compression at $80 \mathrm{~mm} \mathrm{Hg}$ for 4 hours. This magnitude of pressure is known to induce complete ischaemia in the nerve, ${ }^{5}$ and the subsequent endoneurial oedema might be considered a result of increased vascular permeability based upon direct injury to the capillary walls. The diffusion barrier of the perineurium is known to be comparatively resistant to ischaemia. ${ }^{26}$ Thus, the oedema cannot be drained through the perineurial membrane but is accumulated inside the fascicles; a "compartment syndrome in miniature" is constituted. An unexpected finding was a decrease in endoneurial fluid pressure when the compression was applied for time periods exceeding 4 hours. This may be due to an anoxic injury to the perineurium which increases 
with duration of ischaemia, resulting in deterioration of barrier function. One should also consider the possibility of a no-reflow phenomenon in the compressed nerve segment as described by Rydevik et al, ${ }^{5}$ probably based upon severe vascular injury at the edges of the compressed nerve.

Endoneurial oedema may affect nerve function in various ways. A sustained increase in endoneurial fluid pressure may injure nerve fibres. ${ }^{21}{ }^{27} \mathrm{~A}$ change in the electrolyte composition of the endoneurial fluid in association with oedema may impair nerve function. ${ }^{28}{ }^{29}$ Another important factor is possible interference with capillary flow induced by increased tissue pressure. Such a reduction in nerve blood flow in association with increased endoneurial fluid pressure has recently been demonstrated by Myers et $a l .{ }^{30}$ In these experiments, isotope-tracer techniques were used to measure the blood flow in the sciatic nerve of rats suffering from experimental hexachlorophene neuropathy. It was demonstrated that increase of endoneurial fluid pressure from control values around $2.0 \pm 1.0 \mathrm{~cm} \mathrm{H} \mathrm{H}_{2} \mathrm{O}$ to over approximately $6.0 \mathrm{~cm} \mathrm{H} \mathrm{H}_{2} \mathrm{O}$ was associated with a significant reduction in nerve blood flow to about $50 \%$ of control values. Such a reduction of intrafascicular blood flow may be explained by the special microvascular architecture of peripheral nerves. In animal-as well as in human-nerves, anastomosing vessels between the epineurium and endoneurium pass obliquely through openings in the perineurial membrane, ${ }^{12-14}$, thereby constituting a "valve mechanism." An increase in endoneurial fluid pressure may occlude these openings in the perineurium.

It is apparent that the pathophysiology of nerve compression lesions should not be over-simplified and expressed only in terms of mechanical injury with structural changes of myelin and axons. On the contrary, there are reasons to believe that there are important haemodynamic factors involved, and that a local disturbance in the nerve may be based upon microvascular dysfunction and endoneurial oedema with an increase in endoneurial fluid pressure. It is a common surgical experience that rapid decompression of an entrapped nerve sometimes may result in an almost immediate relief of symptoms, an observation which is consistent with neurophysiological measurements performed intraoperatively. ${ }^{31}{ }^{32}$ This immediate relief is probably based upon a rapid improvement of intraneural microvascular flow. Slower resolution of symptoms over days or weeks may be related to gradual disappearance of endoneurial oedema with corresponding reduction in endoneurial fluid pressure, while functional recovery over longer time intervals should be explained in terms of local myelin repair within the compressed segment and/or outgrowth of regenerating nerve fibres.

Supported by grants from the Swedish Medical Research Council No. 5188, The Swedish Work Environment Fund, The Swedish Society for Medical Sciences, The Veterans Administration, The American Heart Association 82-650, NIH Grant NS 14162 .

\section{References}

' Ochoa J, Fowler J, Gilliat RW. Anatomical changes in the peripheral nerves compressed by a pneumatic tourniquet. J Anat 1972;113:433-55.

${ }^{2}$ Gilliat RW. Acute compression block. In: Sumner AJ, ed. The Physiology of Peripheral Nerve Disease. London: Saunders Co, 1980:287-315.

${ }^{3}$ Williams JR, Jefferson D, Gilliat RW. Acute nerve compression during limb ischemia. $J$ Neurol Sci 1980;46:199-207.

${ }^{4}$ Rydevik B, Lundborg G. Permeability of intraneural microvessels and perineurium following acute, graded experimental nerve compression. Scand J Plast Reconstr Surg 1977;11:205-12.

${ }^{5}$ Rydevik B, Lundborg G, Bagge U. Effects of graded compression on intraneural bloodflow. J Hand Surg $1981 ; 6: 3-12$.

${ }^{6}$ Ochoa J. Histopathology of common mononeuropathies. In:Jewett DL, McCarroll Jr Hr eds. Nerve Repair and Regeneration: Its clinical and Experimental Basis. St Louis, Toronto, London: Mosby Co, 1980: 36-52.

${ }^{7}$ Gilliat RW. Chronic nerve compression and entrapment. In: Sumner AJ, ed. The Physiology of Peripheral Nerve Disease. London: WB Saunders Co, 1980: 316-39.

${ }^{8}$ Fullerton PM. The effect of ischaemia on nerve conduction in the carpal tunnel syndrome. $J$ Neurol Neurosurg Psychiatry 1963;26:385-97.

${ }^{9}$ Sunderland S. The nerve lesion in the carpal tunnel syndrome. J Neurol Neurosurg Psychiatry. 1976;39:615-26.

${ }^{10}$ Myers RR, Powell HC, Costello MC, Lampert PW, Zweifach BW. Endoneurial fluid pressure: direct measurement with micropipettes. Brain Res 1978: 148:510-5.

"Rydevik B, Nordborg C. Changes in nerve fibre structure induced by acute, graded compression. J Neurol Neurosurg Psychiatry 1980;43:1070-82.

${ }^{12}$ Lundborg G. Ischemic nerve injury. Experimental studies on intraneural microvascular pathophysiology and nerve function in a limb subjected to temporary circulatory arrest. Scand J Plast Surg 1970;Suppl 6: 1-113.

${ }^{13}$ Lundborg G. Structure and function of the intraneural microvessels as related to trauma, edema formation and nerve function. $J$ Bone Joint Surg 1975;57A:938-48.

${ }^{14}$ Lundborg G. The intrinsic vascularization of human peripheral nerves - structural and functional aspects. $J$ Hand Surg 1979;4:35-41. 
${ }^{15}$ Myers RR, Powell HC, Heckman HM, Costello ML, Katz J. Biophysical and pathological effects of cryogenic nerve lesion. Ann Neurol 1981:10:478-85.

${ }^{16}$ Olsson Y. Studies on vascular permeability in peripheral nerves. I. Distribution of circulating fluorescent serum albumin in normal, crushed and sectioned peripheral nerve. Acta Neuropathol (Berlin) 1966;7:1-15.

${ }^{17}$ Olsson Y, Kristensson K, Klatzo I. Permeability of blood vessels and connective tissue sheaths in the peripheral nervous system to endogenous proteins. Acta Neuropath (Berlin) 1971;Suppl 5:61-9.

${ }^{18}$ Olsson Y, Kristensson $\mathrm{K}$. The perineurium as a diffusion barrier to protein tracers following trauma to nerves. Acta Neuropath (Berlin) 1973;23:105-11.

${ }^{19}$ Rydevik B, Lundborg G. Nordborg C. Intraneural tissue reactions induced by internal neurolysis. Scand J Plast Reconstr Surg 1976;10:3-8.

${ }^{20}$ Myers RR, Powell HC. Endoneurial fluid pressure in peripheral neuropathies. In: Hargens A, ed. Tissue fuid pressure and composition. Baltimore; Williams \& Wilkins Co, 1980:193-214.

${ }^{21}$ Low RA, Dyck PJ. Increased endoneurial fluid pressure in experimental lead neuropathy. Nature 1977;269: 427-8.

${ }^{22}$ Dahlin LB, Danielsen N, McLean WG, Rydevik B, Sjostrand J. Critical pressure levels for impairment of fast axoplasmic transport during experimental compression of rabbit vagus nerve. J Physiol (Lond) 1982;325:84 P.

${ }^{23}$ Gelberman R, Hergenroeder P, Hargens A, Lundborg G, Akeson W. The carpal tunnel syndrome. A study of carpal tunnel pressures. J Bone Joint Surg 1981; 61-A:380-3.

${ }^{24}$ Lundborg G, Gelberman R, Minteer-Convery M, Lee VF, Hargens A. Median nerve compression in the carpal tunnel: the functional response to experimentally induced controlled pressure. J Hand Surg 1982;7:252-59.

${ }^{25}$ Hargens A, Romine J, Sipe J, Evans K, Mubarak S, Akeson W. Peripheral nerve conduction block by high muscle compartment pressure. J Bone Joint Surg 1979;61-A:192-200.

${ }^{26}$ Lundborg G, Nordborg C, Rydevik B, Olsson Y. The effect of ischemia on the permeability of the perineurium to protein tracers in rabbit tibial nerve. Acta Neurol Scand 1973;49:287-94.

${ }^{27}$ Powell HC, Myers RR, Zweifach BW, Lampert PW. Endoneurial fluid pressure in hexachlorophene neuropathy. Acta Neuropathol (Berlin) 1978;41:139-44.

${ }^{28}$ Jacobsen J. Peripheral nerves in early experimental diabetes: expansion of the endoneurial space as a cause of increased water content. Diabetologica 1978;14: 113-9.

${ }^{29}$ Myers RR, Heckman HM, Powell HC. Endoneurial fluid is hypertonic. Results of microanalysis and its significance in neuropathy. J Neuropathol Exp Neurol 1983;42:217-24.

${ }^{30}$ Myers RR, Mizisin AP, Powell HC, Lampert PW. Reduced nerve blood flow in hexachlorophene neuropathy. Relationship to elevated endoneurial fluid pressure. J Neuropathol Exp Neurol 1982; 41:391-9.

${ }^{31}$ Hongell A, Mattsson HS. Neurographic studies before, after and during operation for median nerve compression in the carpal tunnel. Scand J Plast Reconstr Surg 1971;5:103-9.

${ }^{32}$ Eversman W, Ritsick J. Intraoperative changes in motor nerve conduction latency in carpal tunnel syndrome. $J$ Hand Surg 1978;3:77-81. 